\title{
Expansión agrícola y estructura socio-económica en Entre Ríos: el departamento de Paraná a finales del siglo XIX
}

\author{
Agricultural expansion and socio-economic structure in Entre Ríos: The department of Paraná at the end of the $19^{\text {th }}$ \\ century \\ Roberto Daniel Schmit \\ CONICET. Universidad de Buenos Aires. \\ Universidad Nacional de General Sarmiento, Argentina \\ rschmit@ungs.edu.ar
}

Raquel Valeria Bressan

Universidad Nacional de General Sarmiento, Argentina

vbressan@campus.ungs.edu.ar

\section{RESUMEN:}

El presente trabajo realiza una aproximación a la estructura rural del departamento de Paraná durante la década de 1890 a partir del análisis de la distribución socio-ocupacional y del acceso a la tierra de sus pobladores. Sobre la base del análisis cuantitativo de las cedulas censales de población del Censo Nacional de 1895, se reconstruyen y se evalúan, en forma articulada y específica, los perfiles y la localización de los diversos actores emergentes: los agricultores, los colonos, los ganaderos y los que brindaban variados servicios destinados a los diversos mercados. Asimismo, se pondera qué nivel de acceso a la tierra habrían tenido aquellos actores. Palabras Clave: Historia agraria, Estructura rural, Entre Ríos, Agricultura, Siglo XIX.

\section{Abstract:}

This paper analyzes the evolution of rural structure of the department of Parana in the 1890s. From the quantitative analysis of the census, it is reconstructed and weighted in an articulated and specific profiles and location of the various emerging actors: farmers, settlers, ranchers and those who provided various services for the markets. Likewise, we also consider what level of access to land those productive actors would have had.

KEYWORDS: Rural history, Rural structure, Entre Ríos, Agriculture, 19th century.

\section{INTRODUCCIÓN}

A fines del siglo XIX numerosas regiones de la Argentina sostuvieron una notable transformación socioeconómica a partir de los cambios impulsados por las políticas nacionales y provinciales de expansión rural, venta de tierras, promoción de la migración e inmigración, colonización y cambio tecnológico de los medios de circulación y del mundo productivo (Scobie, 1968; Gallo, 1974, 1983; Girbal, 1982; Halperin Donghi,1984; Cortés Conde,1997; Bonaudo y Pucciarelli,1993; Barsky y Gelman, 2001; Barsky y Djenderedjian, 2003; Míguez, 2008; Hora, 2010). Este trabajo examina, en aquel dinámico contexto histórico del país, las características del perfil socio-productivo del departamento de Paraná en la década de 1890. Su finalidad es ponderar adecuadamente la emergencia de los nuevos actores, los tipos de producción y el acceso a la tierra durante el proceso de diversificación y modernización rural.

La provincia de Entre Ríos, a partir del decenio de 1880, comenzaba a superar la etapa previa de una década de notable conflicto e inestabilidad político-institucional que afectó negativamente a la economía rural, y logró registrar desde entonces una transformación de su estructura productiva y un aumento sostenido, sobre 
todo de su actividad agrícola. En esa época, entonces, comenzó a suceder un cambio del patrón productivo que hasta entonces había estado asociado fundamentalmente a la ganadería vacuna y lanar extensiva (Schmit, 2003, 2007; Djenderedjian, 2008a; Schmit y Djendedjian, 2007, 2008; Schmit, 2008, 2015a).

En los últimos veinte años del siglo XIX la expansión agraria entrerriana se convertiría en un hecho significativo, al punto que la superficie cultivada provincial, que era en 1872 sólo de unas 34000 hectáreas, aumentó hasta alcanzar más de 136000 en 1888; y experimentó finalmente otro notable impulso, para registrar 430000 hectáreas en 1895. Es decir que hubo desde 1880 un incremento visible y un posterior desempeño aún mayor en el decenio siguiente. Esa expansión de la producción agrícola entrerriana ponderada a nivel nacional llegó por entonces a representar entre el 5 al $8 \%$ del total del país. ${ }^{1}$

Por tanto, como ya muestra la publicación de los datos generales del censo nacional, para 1895 la provincia de Entre Ríos contaba con una agricultura que sostenía una superficie cultivada de más de 292000 hectáreas de trigo, 72000 de maíz, 19000 de lino, casi 5000 de maní y 16000 de forrajes. Esa dinámica agrícola se complementaba con la presencia de más de 27000 arados y unas 5000 segadoras.

Durante el renovado ciclo rural entrerriano uno de los factores principales de la mudanza productiva rural fue el proceso de la colonización de tipo "radial", en las cercanías o hinterland de las múltiples ciudades y pueblos situados en la campaña. Por lo cual, para mitad de la década de 1890 ya se habían puesto en marcha en la provincia unas 354 colonias, en emprendimientos públicos y privados, dedicadas fundamentalmente a la producción de granos. En ese proceso la acción de colonización estuvo mayormente representada por los empresarios privados; no obstante, también la colonización pública tuvo una presencia más limitada de origen provincial y municipal, pero que ofreció a los colonos parcelas más grandes para la producción agrícola (Djenderedjian, 2008a y b).

No obstante la importancia de la colonización entrerriana, como ya han mostrado los estudios de Djenderedjian (2008a y b, 2013, 2014), también es muy significativo evaluar en detalle, para los diferentes departamentos de la provincia, la emergencia de otros importantes actores y factores de ese proceso, como la creciente presencia en la reconversión productiva de agricultores (inmigrantes, locales, propietarios, arrendatarios y medieros) en la campaña y en los ejidos, y visualizar las actividades en los pueblos y suburbios durante la época.

Asimismo, en relación con la estructura productiva es importante evaluar la pervivencia de la ganadería y sus potenciales adaptaciones a la mestización, como también otros varios sectores de servicios vinculados con la demanda de la urbanización en la región y en las provincias vecinas. Por lo tanto, es evidente, entonces, que más allá de observar a nivel macro el cambio del patrón productivo que implicó la colonización es necesario profundizar en el carácter específico de un conjunto de transformaciones socio-económicas en la reconversión y la diversificación de la estructura de la economía rural de fines del siglo XIX (Schmit, 2010 y 2015b; Schmit y Alabart, 2013).

Para evaluar concretamente los cambios integrales en el interior del territorio entrerriano, en su estructura socio-económica y en su dinámica de acceso a la propiedad, contamos con pocos estudios. Asimismo, los disponibles se caracterizan por una dualidad ya que, por una parte, nos ilustran sobre todo las características macro del proceso general en la provincia o, por otra, analizan fundamentalmente en forma general a las colonias -en algunos casos abordan el estudio de caso de alguna colonia agrícola- (Popp y Dening, 1977; Weyne, 1987 y 1988; Rodríguez y Flores, 2006). No contamos aún con estudios intermedios que nos muestren un panorama departamental o regional más equilibrado sobre la estructura global de producción, en el que podamos considerar en forma articulada, integral y específica todos los nuevos perfiles interrelacionados de los diversos actores: los agricultores, los colonos, los ganaderos y los que brindaban diversos servicios destinados a los mercados locales de cercanías o a los mercados nacionales. Así como también podamos evaluar el nivel de acceso a la tierra que tuvieron los diversos sectores productivos.

Justamente, en función de abordar las cuestiones mencionadas desde enfoques intermedios, en este artículo estudiamos las transformaciones rurales integrales para el caso del departamento de Paraná. Este 
departamento, además de contener la ciudad capital de la provincia y de disponer de un puerto fluvial muy activo que se vinculaba con todo el Litoral y con ultramar, fue un territorio con una campaña relevante que se reflejó en su dinámica productiva, que acompañó activamente el proceso de cambio socio-económico en la provincia de Entre Ríos (Schmit y Djenderedjian, 2011 y 2012). Así, el departamento de Paraná también fue un espacio territorial que sostuvo la tendencia de expansión del universo productivo agrícola entrerriano, alcanzando registros del 15\% del total de la superficie cultivada provincial a mediados del decenio de 1890 .

Para el análisis de la estructura socio-ocupacional en el área rural de Paraná nos basaremos como fuente principal en las cedulas censales demográficas del Censo Nacional de $1895 .^{2}$ Ellas nos permiten visualizar las diversas estructuras socio-económicas de las unidades censales relevadas, así como contar con información específica sobre la constitución y las características de los habitantes del mundo rural, entre las cuales son muy relevantes su origen, ocupación, tipo de producción y acceso a la tierra. Por ello, mediante el análisis agregado de las unidades censales podemos disponer de una visión general del mapa del mundo rural de Paraná. ${ }^{3}$ Además, nos permitirá hacer comparaciones temporales relevantes entre las mutaciones y las novedades del departamento a fin de siglo y el perfil y estructura productiva de origen que relevan los censos departamentales provinciales precedentes, recopilados por las autoridades locales de las jefaturas políticas de la década de 1860.

\section{La estructura rural del departamento de Paraná}

A fines del siglo XIX, sin duda Paraná ya era un departamento que había comenzado a adoptar un registro socio-productivo complejo, por lo cual en los distritos cercanos a la ciudad y en las cercanías de la costa del río habían progresado aceleradamente la agricultura y la colonización, en tanto en las zonas de tierra adentro hacia el centro de la provincia, en los distritos de Quebracho y de María Grande I y II, se mantenía la presencia significativa de las producciones ganaderas con sus típicas estancias vacunas.

De modo que un primer mapeo socio-productivo territorial del departamento para el decenio de 1890 muestra que en los distritos de Sauce, Espinillo, Tala y Antonio Tomás funcionaba plenamente una estructura de producción diversificada y con un activo movimiento mercantil y artesanal. En Sauce se habían instalado las colonias Tres de Febrero y María Luisa, y el poblado de Tres de Febrero. En Espinillo se encontraban la colonias Merou y Crespo, junto con los pobladores de la Villa San José y de la Estación Crespo. En el distrito Tala estaban las colonias Villa Urquiza, Celina, Aldea Santa María, y gran parte de Colonia Crespo y Cerrito. También en las cercanías se situaban los poblados de Racedo y del Cerrito. Finalmente, en Antonio Tomás se encontraban las colonias Hernandarias y Brugo, parte de colonia Cerrito y los poblados de Hernandarias y el pueblo General San Martín, con sus respectivos hinterland de chacras.

Por todo el conjunto señalado, el departamento de Paraná sumaba más de cuatro mil unidades censales, dentro de las cuales se registraba un peso interesante de las colonias y de algunos pueblos que contaban con el $20,6 \%$ y el $11,1 \%$ de las unidades censales (UC) ${ }^{5}$, respectivamente, lo que sumaba un total de $31,7 \%$ por ciento de las UC de toda la campaña paranaense. No obstante, esas novedades del mundo rural en el Departamento todavía mantenían un claro predominio del peso de las estancias y de un número significativo de otros productores agrícolas, que en conjunto acumulaban el 67,4\% del total de UC. ${ }^{6}$ 
TABLA 1

Distribución de UC por distrito rurales y en pueblos Paraná. 1895

\begin{tabular}{|l|r|r|r|r|}
\hline \multicolumn{1}{|c|}{ Distrito } & UC Rural & UC Colonia & UC Pueblo & Total UC \\
\hline Sauce & 155 & 78 & 45 & 278 \\
\hline Espinillo & 690 & 77 & 134 & 901 \\
\hline Tala & 331 & 423 & 161 & 961 \\
\hline Antonio Tomás & 457 & 277 & 120 & 854 \\
\hline Quebracho & 513 & 0 & 0 & 513 \\
\hline María Grande I & 454 & 0 & 0 & 454 \\
\hline María Grande II & 196 & 0 & 0 & 196 \\
\hline Total & 2.796 & 855 & 460 & 4.157 \\
\hline$\%$ & 67,4 & 20,6 & 11,1 & 100 \\
\hline
\end{tabular}

Fuente: Archivo General de la Nación (AGN), Censo Nacional de Población de 1895, Cédulas Censales de Población correspondientes al Departamento de Paraná, Entre Ríos

La estructura productiva rural paranaense se distribuía en sus distritos mediante un sector productivo compuesto por tres grandes sectores: los ganaderos, los agricultores y los colonos, que acumulaban en conjunto el 49,55 \% de las unidades censales. A ello se sumaba otro 11,6\% de trabajadores ligados al mundo rural de peones y jornaleros. Completaban el panorama un grupo de poblados en los ejidos de los pueblos de General San Martín, Hernandarias, Racedo, Tres de Febrero, Villa San José y Estación Crespo, con el 11,1 $\%$ de unidades censales de actores ligados a modestos agricultores, a chacareros y al sector servicios, de oficios artesanales y de trabajo doméstico. En particular, en el sector de oficios y servicios se destacaban las actividades de los comerciantes, carreros, carpinteros, carniceros, panaderos, fonderos, abastecedores, ladrilleros y el trabajo doméstico de costureras y lavanderas.

Sin embargo, para un análisis más específico sobre las características de la estructura productiva de la campaña paranaense procederemos a presentar en diferentes apartados los más significativos tipos de unidades productivas. En primer término, analizamos a los productores rurales de la campaña y en segundo lugar, a los actores productivos de las colonias.

\section{EsTruCTURA DE PRODUCCIÓN EN LA CAMPAÑA}

La campaña paranaense contenía una mayoría de agricultores con unidades productivas de diversos tipos, las mismas alcanzaban más de 800 UC y en su mayoría producían trigo. En segundo orden se encontraban las estancias ganaderas, que alcanzaban más de 400 UC. Pero en su distribución espacial había una clara diferencia entre los distritos cercanos a la ciudad de Paraná, en cuyo hinterland predominaba claramente la agricultura, y los otros de tierra adentro (en los distritos de Quebracho y de María Grande I y II), donde predominaban ampliamente las estancias. Para complementar esta caracterización, había unas 67 UC de jornaleros y peones que interactuaban con diversos tipos de establecimientos rurales.

Más de 350 UC estaban encabezadas por actores que realizaban actividades de servicios, fundamentales comerciantes y carreros, pero también otros. Así, el registro socio-económico rural paranaense, liderado por los agricultores y estancieros, era de carácter diversificado. 
TABLA 2

Tipo de ocupación. Distribución por distrito Paraná 1895

\begin{tabular}{|l|r|r|r|r|r|r|}
\hline \multicolumn{1}{|c|}{ Distrito } & \multicolumn{1}{c|}{$\begin{array}{c}\text { UC } \\
\text { Ganaderas }\end{array}$} & $\begin{array}{c}\text { UC } \\
\text { Agrícolas }\end{array}$ & $\begin{array}{c}\text { UC } \\
\text { Agrícolas } \\
\text { en } \\
\text { Colonias }\end{array}$ & $\begin{array}{c}\text { UC } \\
\text { oficios y } \\
\text { servicios }\end{array}$ & $\begin{array}{c}\text { UC } \\
\text { peón y } \\
\text { jornaleros }\end{array}$ & $\begin{array}{r}\text { UC } \\
\text { SD }\end{array}$ \\
\hline Sauce & 5 & 117 & 58 & 43 & 24 & 29 \\
\hline Espinillo & 32 & 388 & 62 & 214 & 97 & 41 \\
\hline Tala & 55 & 175 & 235 & 285 & 50 & 35 \\
\hline Antonio & 64 & 131 & 139 & 319 & 54 & 43 \\
Tomás & 111 & 61 & 0 & 176 & 95 & 70 \\
\hline Quebracho & 119 & 33 & 0 & 160 & 73 & 69 \\
\hline María Gra. I & 69 & 1 & 0 & 40 & 67 & 19 \\
\hline María Gra II & 455 & 906 & 494 & 1237 & 460 & 306 \\
\hline Total & & & & & & \\
\hline
\end{tabular}

Fuente: AGN, Censo Nacional de Población de 1895, Cédulas Censales de Población correspondientes al departamento de Paraná, Entre Ríos. La categoría "ganaderas" corresponden a los que declaran estancia en el censo. La categoría "Agrícolas" considera a los que declaran ser agricultor. La categoría "Agrícola en Colonias" considera a los que se declaran colonos o agricultores en las colonias. La categoría "peón y jornalero" se toma del censo. La categoría "Oficios y servicios”, en cambio, engloba múltiples ocupaciones registradas en el censo. UC S-D=unidad censal sin datos.

Si comparamos las principales transformaciones rurales paranaenses ocurridas entre las décadas de 1860 y 1890, podemos señalar varias cuestiones que caracterizaron ese proceso. En términos generales, una primera cuestión fue el gran aumento que registraron las unidades censales, que pasaron de 991 a más de 4000 , lo que muestra que entre esas décadas hubo un incremento notable. En tanto, su distribución al interior de los distritos indica también otras mutaciones significativas: si en el período inicial se destacaban como más densamente poblados los distritos de Sauce y de María Grande I, para fines de siglo las más destacadas serían las del núcleo integrado por la nueva área agrícola de los distritos de Tala, Espinillo y Antonio Tomas.

Asimismo, lo más notable fue, naturalmente, el incremento enorme de la superficie cultivada, así como un cambio destacado n las características productivas al interior de los distritos. Así, para 1861 el trigo y el maíz se producían sobre todo en Sauce y en María Grande I y II, es decir al interior de las estancias. Para 1895, las zonas principales de los granos ya se encontraban situadas en Tala, Espinillo y Antonio Tomás en manos de los agricultores y las colonias. En tanto, la ganadería pasó de ser homogénea y estar distribuida en forma bastante pareja en todos los distritos, con una pequeña supremacía en María Grande I, a situarse muy concentrada en los distritos de tierra adentro de María Grande I y II, y en menor medida en Quebracho a fin de siglo.

Esta primera breve descripción global marca la transición espacial, productiva y social que se generó al interior del departamento entre el final de la época de supremacía del perfil ganadero extensivo y la nueva etapa de predominio agrícola-ganadero que, como señalamos, implicó la reconversión del perfil y de la magnitud productiva del universo rural entrerriano.

En relación con las características generales de la estructura productiva de Paraná, para 1895 fue notable el cambio respecto del origen que tenían los jefes de las UC. Si bien la mayoría era entrerriana (el $59 \%$ en más de 1.600 UC), era muy notable el peso que habían alcanzado los europeos (el $34 \%$ en 944 UC). Completaban el universo los oriundos de otras provincias y de otros países limítrofes a Entre Ríos. 
TABLA 3

Origen del jefe de UC. Distribución por distrito 1895

\begin{tabular}{|l|r|r|r|r|r|r|r|r|}
\hline \multirow{2}{*}{ Distrito } & \multicolumn{2}{|c|}{ Entre Ríos } & \multicolumn{2}{|c|}{ Otras provincias } & \multicolumn{2}{c|}{ Europeos } & \multicolumn{2}{|c|}{ Otros } \\
\cline { 2 - 9 } & Prop. & No-Prop & Prop. & $\begin{array}{c}\text { No- } \\
\text { Prop. }\end{array}$ & Prop. & $\begin{array}{c}\text { No- } \\
\text { Prop. }\end{array}$ & Prop. & $\begin{array}{c}\text { No- } \\
\text { Prop. }\end{array}$ \\
\hline Sauce & 39 & 21 & 1 & 1 & 56 & 32 & 1 & 1 \\
\hline Espinillo & 97 & 127 & 15 & 26 & 198 & 218 & 1 & 5 \\
\hline Tala & 72 & 74 & 7 & 6 & 120 & 46 & 2 & 4 \\
\hline Antonio Tomás & 94 & 182 & 13 & 23 & 73 & 65 & 1 & 2 \\
\hline Quebracho & 160 & 246 & 11 & 18 & 19 & 35 & 2 & 8 \\
\hline María Gran. I & 137 & 205 & 7 & 16 & 24 & 48 & 2 & 3 \\
\hline María Gran. II & 115 & 59 & 11 & 5 & 6 & 4 & 3 & 0 \\
\hline Total & 714 & 914 & 65 & 95 & 496 & 448 & 12 & 23 \\
\hline
\end{tabular}

Fuente: AGN, Censo Nacional de Población de 1895, Cédulas Censales de Población correspondientes al departamento de Paraná, Entre Ríos. Prop. = propietario. No-prp. =no propietario

Si analizamos el $34 \%$ de las UC rurales con jefes de origen europeo, podemos observar que en su mayoría se trataba de italianos $(36,7 \%)$ y rusos -alemanes del Volga- $(32,4 \%)$, seguidos de austríacos, franceses, españoles, alemanes y suizos.

TABLA 4

$\mathrm{UC}$ con jefes de origen europeo

\begin{tabular}{|c|c|c|c|c|c|c|c|c|}
\hline Distrito & Rusia & Italia & Francia & Austria & Suiza & Alemania & España & Otros \\
\hline Sauce & 0 & 40 & 6 & 35 & 6 & 1 & 3 & 0 \\
\hline Espinillo & 212 & 110 & 21 & 21 & 12 & 18 & 20 & 3 \\
\hline Tala & 76 & 51 & 15 & 4 & 7 & 7 & 5 & 1 \\
\hline A. Tomás & 18 & 65 & 7 & 20 & 4 & 12 & 13 & 1 \\
\hline Quebracho & 0 & 37 & 5 & 1 & 3 & 3 & 6 & 1 \\
\hline María Gra. I & 0 & 38 & 8 & 3 & 0 & 4 & 9 & 1 \\
\hline María Gra. II & 0 & 6 & 1 & 0 & 0 & 0 & 3 & 0 \\
\hline Total & 306 & 347 & 63 & 84 & 32 & 45 & 59 & 7 \\
\hline
\end{tabular}

Fuente: AGN, Censo Nacional de Población de 1895, Cédulas Censales de Población correspondientes al departamento de Paraná, Entre Ríos

En suma, el conjunto más significativo de los nuevos actores se encontraba en un núcleo de productores agrícolas con diverso tipo de acceso a la tierra. En proporciones casi similares, se trataba de actores entrerrianos volcados a la agricultura, como otros europeos arribados a la provincia desde el decenio de 1880 . Estos extranjeros, junto a un conjunto modesto de migrantes nacionales, constituyeron el principal segmento productivo agrícola paranaense. 


\section{ESTRUCTURA DE PRODUCCIÓN EN LAS COLONIAS}

En las colonias, las UC estaban dedicadas mayormente a la actividad agrícola, ya que alcanzaban el 59,7 \% del total. En tanto, los trabajadores dependientes de este universo rural representaban el 6,9\%, por lo cual el sector productivo agrario sumaba el $66,6 \%$ del total. Una porción significativa del $33,4 \%$ restante se repartía entre ocupaciones de oficios y otros. De esta manera, el universo de las colonias replicaba características del resto de la campaña paranaense. Sin embargo, dentro del colectivo de las colonias había claras diferencias. Villa Urquiza, Cerrito y Tres de Febrero eran más antiguas y estaban situadas en las cercanías de la ciudad de Paraná. Además de un núcleo agrícola de colonos, éstas registraban (entre el 70 y $80 \%$ del total) un notable sector mercantil y de servicios de transportes junto con diferentes oficios del sector artesanal. En contraste, las colonias de Merou, Crespo, Aldea Santa María y María Luisa contaban con una predominante especialización agrícola y registraban un muy pequeño sector comercial y de servicios.

TABLA 5

Estructura de ocupación en las colonias de Paraná

\begin{tabular}{|l|r|r|r|r|r|r|}
\hline \multicolumn{1}{|c|}{ Colonia } & Agricultores & Ganaderos & $\begin{array}{c}\text { Jornaleros } \\
\text { Peones }\end{array}$ & $\begin{array}{c}\text { Comerciante } \\
\text { Oficios }\end{array}$ & Otros & Total \\
\hline Cerrito (AT-T) & 103 & 1 & 16 & 35 & 44 & 199 \\
\hline Hernandarias (AT) & 31 & 6 & 3 & 5 & 19 & 64 \\
\hline Brugo (AT) & 5 & 0 & 0 & 0 & 9 & 14 \\
\hline V. Urquiza(T) & 147 & 9 & 26 & 54 & 71 & 307 \\
\hline Celina (T) & 10 & 0 & 4 & 0 & 0 & 14 \\
\hline Crespo(T y E) & 48 & 0 & 0 & 0 & 20 & 68 \\
\hline Merou (E) & 47 & 0 & 0 & 0 & 4 & 51 \\
\hline T. Febrero(S) & 17 & 0 & 2 & 9 & 1 & 29 \\
\hline M. Luisa(S) & 41 & 0 & 4 & 0 & 4 & 49 \\
\hline Aldea Sta. María (T) & 45 & 0 & 3 & 3 & 9 & 60 \\
\hline Total & 494 & 16 & 58 & 106 & 181 & 855 \\
\hline$\%$ & 57,8 & 1,9 & 6,8 & 12,4 & 21,1 & 100 \\
\hline
\end{tabular}

Fuente: AGN, Censo Nacional de Población de 1895, Cédulas Censales de Población correspondientes al departamento de Paraná, Entre Ríos. $(\mathrm{AT})=$ Antonio Tomás. $(\mathrm{T})=$ Tala. $(\mathrm{E})=$ Espinillo. $(\mathrm{S})=$ Sauce

La complejidad de orígenes, localización y evolución socio-económica marca un escenario desigual en los diferentes tipos de colonias del departamento de Paraná: las colonias de vieja data como Villa Urquiza se fueron transformando notablemente desde los años de su temprana fundación y mostraban a fines de siglo un registro de inmigrantes, aunque también se habían incorporado muchos actores locales y regionales. Un proceso similar se observa en otras colonias grandes, como Cerrito, Hernandarias, Brugo y Celina. Diferente era el caso de otras colonias nuevas, como Aldea Santa María y Merou, que registraban un alto índice de uniformidad étnica (con inmigrantes europeos) y que no tenían ningún colono local. Sin embargo, también se registraron casos de colonias nuevas, como Crespo y María Luisa, que contenían una baja dotación de actores nativos. Por ello, en esos últimos conjuntos de colonias podríamos decir que se presentaba una identidad propia como comunidad étnica-cultural, con un alto peso en ellas de los llamados "rusos o alemanes del Volga" junto con otros actores también de origen europeo. 
TABLA 6

Origen de los colonos del departamento de Paraná 1895

\begin{tabular}{|l|r|r|r|r|r|r|r|r|}
\hline \multicolumn{1}{|c|}{ Colonia } & Rusia & Italia & Francia & Alem. & Austria & $\begin{array}{l}\text { Otros } \\
\text { paises }\end{array}$ & $\begin{array}{l}\text { Entre } \\
\text { Rios }\end{array}$ & $\begin{array}{l}\text { Otras } \\
\text { prov. }\end{array}$ \\
\hline Cerrito & 0 & 81 & 8 & 8 & 16 & 14 & 63 & 9 \\
\hline Hernandarias & 0 & 10 & 4 & 2 & 1 & 10 & 34 & 3 \\
\hline Brugo & 0 & 2 & 0 & 0 & 2 & 1 & 7 & 1 \\
\hline V. Urquiza & 19 & 33 & 17 & 33 & 5 & 47 & 138 & 25 \\
\hline Celina & 0 & 4 & 1 & 0 & 1 & 2 & 4 & 2 \\
\hline Crespo & 18 & 13 & 4 & 2 & 7 & 10 & 5 & 1 \\
\hline Merou & 48 & 0 & 0 & 0 & 0 & 1 & 2 & 0 \\
\hline T de Febrero & 0 & 11 & 1 & 0 & 12 & 1 & 2 & 1 \\
\hline M. Luisa & 47 & 0 & 1 & 0 & 0 & 0 & 1 & 0 \\
\hline Aldea Sta. & 53 & 1 & 0 & 3 & 1 & 2 & 0 & 0 \\
María & 185 & 155 & 36 & 48 & 45 & 88 & 256 & 42 \\
\hline Total & & & & & & & & \\
\hline
\end{tabular}

Fuente: AGN, Censo Nacional de Población de 1895, Cédulas Censales de Población correspondientes al departamento de Paraná, Entre Ríos. E. Ríos = entrerrianos. Otros Prov. = otros nacionales

En cuanto a la relación entre ocupación y origen, en las colonias el peso de los inmigrantes era también mucho mayor en el segmento de los productores agrícolas y de oficios, mientras que los colonos nativos (entrerrianos y regionales) se destacaron dentro del sector mercantil y de transportes, que fueron significativos para lograr un adecuado funcionamiento de la economía agrícola.

Por tanto, dentro de la estructura socio-ocupacional paranaense, si bien la colonización fue un proceso que estuvo asociado fuertemente a la expansión agraria, entre las colonias existió un universo diverso que matiza la mirada general de sus características en comparación con el universo agrario local. En ella se pueden observar dos tipos de dinámicas temporales y de composición socio-étnica, así como de perfil ocupacional predominante.

\section{Acceso a la tierra en la Campaña de Paraná}

En este apartado, sobre la base de la información disponible del censo, abordamos la cuestión de cuál fue el grado de acceso a la tierra que tuvieron los diversos actores del mundo rural de Paraná durante el proceso analizado. Para responder la pregunta, en primer lugar es necesario considerar, como ya hemos señalado en otros estudios, que desde la sanción de las leyes de tierras en 1861 hubo numerosas y recurrentes dificultades en Entre Ríos para la regularización y registro de la propiedad y usufructo de la tierra pública y privada. En ese contexto, el departamento de Paraná no fue una excepción, como lo muestran los limitados estados de los datos oficiales de la provincia. ${ }^{7}$

Luego de la derrota de la primera rebelión de Ricardo López Jordán, el gobierno provincial buscó reimpulsar el proceso de ordenamiento rural. Por lo tanto, en 1871 el Departamento Topográfico fue reestructurado y se centralizó en ese organismo todo lo relativo al ordenamiento territorial de la provincia. ${ }^{8}$ De modo tal que una parte significativa de las tareas del Departamento se concentró en el archivo y registro de títulos de propiedad, posesión y arrendamiento, y también, en la mensura y la delineación de los terrenos. La información acumulada se reunía en principio en los registros departamentales a partir de la presentación voluntaria de los propietarios y se remitía luego al Departamento Topográfico, que estaba a cargo, finalmente, de confeccionar el registro general de tierras y la carta topográfica de la provincia. ${ }^{9}$

A partir de la información reunida en la agencia pública se elaboraron para la provincia tres mapas sobre la propiedad en 1873, 1886 y 189,2 y un informe catastral general en 1879 (González, 1874; Guzmán y Rígoli, 
1886; Nolte, 1892; Ministerio de Gobierno de Entre Ríos, 1879). El último documento mencionado fue el único registro disponible que daba cuenta concreta de las diversas formas de acceso a la propiedad. Así, según aquella información, en el departamento de Paraná el acceso a la tierra se realizaba mayoritariamente en forma de arriendo y los propietarios alcanzaban sólo el 34,4\% de la población registrada. Sin embargo, al discriminar los datos por distrito, el porcentaje de propietarios en las zonas agrícolas resultaba sensiblemente mayor, con un $59,1 \%$ en el distrito de Sauce y un $61,9, \%$ en el de Tala. ${ }^{10}$

Pero para estimar la representatividad de los datos hay que considerar que la elaboración del sistema de recopilación de información oficial dependía de la voluntad de los individuos para regularizar sus registros, por lo cual seguramente reflejan sólo en forma muy parcial e incompleta el universo ya existente de propietarios y no propietarios en aquella época. Asimismo, por ejemplo, si tomamos los datos del censo nacional de 1869 para evaluar los registros disponibles para 1879 (de una década antes), ese registro sólo alcanzaba a representar el 2,25\% de la población rural del departamento de Paraná.

Por lo tanto, si bien los datos oficiales para inicio de la expansión agrícola de 1880 nos permiten entrever algunas tendencias que se irían acentuando en los siguientes años, ya ponen en evidencia también la muy limitada capacidad de las agencias estatales para generar información actualizada y un control efectivo sobre el acceso a la propiedad y la tierra pública. Por consiguiente, la brecha entre los datos adquiridos en los registros estatales oficiales y las condiciones territoriales existentes se tornaría un problema aún mayor para la gestión provincial durante las décadas de 1880 y 1890 , cuando los cambios de la estructura de propiedad se volvieron mucho más dinámicos.

De acuerdo con los datos expresados por los pobladores para 1895, el 43,4 \% de los jefes de las UC se habían declarado como "propietarios", lo que nos señalaría un porcentaje elevado de pobladores con acceso a la tierra. Asimismo, tomando una mirada más detallada por distrito, se puede observar que en Sauce y Tala se encontraban los mayores porcentuales de acceso (más del $60 \%$ ), seguidos por Espinillo con un 45\% y finalmente Antonio Tomás, Quebracho y María Grande I y II con entre 31 y 39 \%. Esa distribución nos estaría indicando que había mayor acceso a la tierra en las UC de los distritos de predominio agrícola y menor en los distritos ganaderos.

TABLA 7

Propietarios y no propietarios en la campaña de Paraná

\begin{tabular}{|l|r|c|r|r|r|}
\hline \multicolumn{1}{|c|}{ Distrito } & Propietario & $\%$ & $\begin{array}{c}\text { No } \\
\text { propietario }\end{array}$ & $\%$ & Total \\
\hline Sauce & 100 & 64,5 & 55 & 35,5 & 155 \\
\hline Espinillo & 312 & 45,2 & 378 & 54,8 & 690 \\
\hline Tala & 203 & 61,3 & 128 & 38,7 & 331 \\
\hline Antonio Tomás & 164 & 36,1 & 292 & 63,9 & 456 \\
\hline Quebracho & 194 & 37,8 & 319 & 62,2 & 513 \\
\hline María Gran. I & 171 & 38,5 & 273 & 61,5 & 444 \\
\hline María Gran. II & 61 & 31,1 & 135 & 68,9 & 196 \\
\hline Total & 1.216 & 43,4 & 1.580 & 56,6 & 2.796 \\
\hline
\end{tabular}

Fuente: AGN, Censo Nacional de Población de 1895, Cédulas Censales de Población correspondientes al departamento de Paraná, Entre Ríos 
Respecto del acceso a la tierra a partir de la actividad productiva de los jefes de UC, podemos estimar que habrían accedido a ella el $79 \%$ de los estancieros, el $55 \%$ de los agricultores, el $48 \%$ de los comerciantes y carreros, el $43 \%$ de los oficios, el $11 \%$ de los peones y el $10 \%$ de los carboneros y hacheros.

Asimismo, debemos tener en cuenta que para las colonias estatales las formas de acceso a la tierra y la propiedad sufrieron modificaciones entre las décadas de 1860 y 1890 . Durante la etapa de fundación temprana de las primeras colonias, como la de Villa Urquiza, el gobierno dispuso la concesión gratuita de los terrenos bajo la condición que fuesen poblados y cultivados. Cumplidas las condiciones por un lapso de tres años, los poseedores podían escriturar en propiedad sus parcelas. ${ }^{11}$ Pero a medida que se ampliaba el ejido de las ciudades y comenzaba a cobrar mayor impulso el proceso colonizador, el acceso gratuito a las tierras en las colonias establecidas en terrenos fiscales de la provincia o el municipio fue sustituido por una suma fija que debía ser abonada en cuotas. ${ }^{12}$ La disposición fue modificada nuevamente en 1884, cuando la legislatura aprobó la elaboración del catastro de las colonias de propiedad de la provincia. Por medio de esta ley ya no se establecía un único precio general sino un precio mínimo que se modificaba de acuerdo con su ubicación departamental. En este sentido, resulta relevante el índice de acceso a la propiedad pues Paraná representaba uno de los departamentos con precios más altos para las parcelas a colonizar. ${ }^{13}$

Según los datos del censo nacional de 1895, en las colonias el acceso a la tierra alcanzaba un promedio de casi un $58 \%$ de las UC, un porcentual mayor en un 14\% con respecto a los restantes sectores de la campaña paranaense. Esos valores también eran muy diferenciales entre ellas, con un porcentaje de mayor peso en Tres de Febrero (75\%), Villa Urquiza (63\%) y Hernandarias (62 \%). Otro segmento intermedio se daba en Cerrito (58 \%), Merou (57\%), Aldea Santa María (55\%) y Crespo (50\%). Finalmente, había un conjunto de colonias nuevas donde predominaban los "no propietarios": todos en Brugo, el 43 \% en Celina, el $22 \%$ en María Luisa.

TABLA 8

Propietarios y no propietarios en las colonias de Paraná

\begin{tabular}{|l|r|c|r|r|r|}
\hline \multicolumn{1}{|c|}{ Colonia } & Propietario & $\%$ & $\begin{array}{c}\text { No } \\
\text { propietario }\end{array}$ & $\%$ & Total \\
\hline Cerrito & 115 & 57,8 & 84 & 42,2 & 199 \\
\hline Hernandarias & 40 & 62,5 & 24 & 37,5 & 64 \\
\hline Brugo & 0 & 0 & 14 & 100,0 & 14 \\
\hline V. Urquiza & 193 & 62,9 & 114 & 37,1 & 307 \\
\hline Celina & 6 & 42,8 & 8 & 57,2 & 14 \\
\hline Crespo & 34 & 50,0 & 34 & 50,0 & 68 \\
\hline Merou & 29 & 56,9 & 22 & 43,1 & 51 \\
\hline Tres de Febrero & 22 & 75,9 & 7 & 24,1 & 29 \\
\hline M. Luisa & 38 & 22,5 & 11 & 77,5 & 49 \\
\hline Aldea Sta. María & 33 & 55,0 & 27 & 45,0 & 60 \\
\hline Total & 510 & 59,6 & 345 & 40,4 & 855 \\
\hline
\end{tabular}

Fuente: AGN, Censo Nacional de Población de 1895, Cédulas Censales de Población correspondientes al departamento de Paraná, Entre Ríos

Respecto del acceso a la tierra en las colonias, si tomamos los datos solamente del sector de los colonos dedicados a la agricultura los promedios muestran un panorama algo diferente. En este segmento productivo vital, el promedio de "propietarios" alcanzaba el 78,9\% de las unidades censales, un promedio muy alto (un 23 
\% mayor que el resto de los agricultores de la campaña paranaense) que nos estaría señalando una significativa capacidad de acceso a la tierra de los agricultores en las colonias.

En las colonias, el alto promedio en general de los colonos agricultores con acceso a la tierra varía entre los que superan el 80 \% en Cerrito, Tres de Febrero, Crespo, Villa Urquiza y María Luisa, y los que van de 50 a 80 $\%$ en Aldea Santa María, Hernandarias, Merou y Celina. Por último, estaba el caso atípico de colonia Brugo, que recién daba sus primeros pasos, aún sin ningún propietario y con un registro productivo de predominio de hacheros y carboneros que por entonces despejaban el terreno de los densos montes entrerrianos.

Si tomamos en consideración el origen de los colonos y el acceso a la tierra, también resulta muy visible que tuvieron un peso más importante los colonos inmigrantes europeos. Ellos se distinguen, como indicamos, como actores relevantes de la puesta en marcha de varias colonias. Suman 543 unidades censales (el 63,5\% del total), entre rusos-alemanes del Volga, alemanes, italianos, austríacos, franceses, suizos, españoles y, en menor medida, los belgas y dinamarqueses. También hay una minoría de sólo 14 casos de colonos procedentes de Brasil, Uruguay y Paraguay. Pero, asimismo, se debe considerar como muy relevante la presencia de las 256 UC de entrerrianos, que acumulan el 29,9\% del total, así como de colonos de otras provincias como Santa Fe, Córdoba, Corrientes, Buenos Aires y San Luis, con el 4,9\%. De manera que se debe considerar que el $36,5 \%$ de los jefes de UC de colonos eran nativos o de otras provincias y de países vecinos.

Así, la información que presentan los registros censales de las UC sobre el acceso a la tierra nos permite, en primer lugar, realizar una primera ponderación sobre la situación que haría visible un índice significativo de acceso a la tierra. También indicaría tendencias diferenciales respecto de la marcha muy lenta y parcial de las declaraciones de los pobladores y de los registros oficiales recopilados en el registro de la provincia. En segundo lugar, nos invita a explorar otras cuestiones muy significativas sobre qué tipo de acceso a la tierra habrían tenido los actores "propietarios", ya fuera en propiedad, usufructo, arriendo u otras formas de arreglos privados y públicos, por lo cual esta información deberá ser cruzada a futuro con los datos de los registros de cercos de otra sección del censo nacional, a fin de dar cuenta de manera más precisa de la naturaleza del acceso y de su distribución en tamaño en la estructura productiva entrerriana.

\section{Conclusiones}

En este trabajo se analizaron las transformaciones en la estructura socio-ocupacional rural entrerriana de las últimas décadas del siglo XIX a partir del estudio del perfil productivo y del acceso a la tierra en el departamento de Paraná. Como ya señalamos, la reconversión rural en el caso entrerriano radicó en que su proceso de cambio productivo no fue impulsado por la incorporación de nuevas tierras con base en la expansión sobre las fronteras de la provincia sino mediante una sostenida reconversión de una economía previa de producción ganadera extensiva a una de un perfil agrario y ganadero más intensiva.

En primer lugar, se debe destacar el impacto del cambio alcanzado entre las décadas de 1860 a 1890 con un crecimiento superlativo de la superficie cultivada. Aquel cambio se correspondió con la emergencia de una estructura de producción y de servicios diversificada en la que las actividades agrícola-ganaderas convivían con un conjunto creciente de pequeños núcleos dedicados al comercio y a los oficios. Así, en los distritos rurales de Paraná las UC dedicadas a la agricultura representaron el 33,1 \%, las de los ganaderos el 16,8 \% y un $23,4 \%$ correspondía a los comerciantes y a los que se desempeñaban en diversos oficios.

El entramado socio-productivo de las UC tuvo una territorialidad bien definida. Así, en los distritos de Quebracho y María Grande I y II, los más alejados de la ciudad y la costa, estuvieron instaladas mayoritariamente las unidades productivas ganaderas. En tanto, en Sauce, Tala, Espinillo y Antonio Tomás se destacaron los agricultores y las colonias que fundamentalmente se dedicaban a las tareas del cultivo y a los ramos diversos de los servicios. Finalmente, la presencia del comercio se hallaba en todos ellos, pero con un peso porcentual diferenciado del siguiente modo: Sauce $12 \%$, Espinillo 16,2 \%, Tala 17,8 \%, Antonio Tomás $42 \%$, Quebracho, 33,9 \%, María Grande I 34,8 \% y María Grande II $23 \%$. 
En el nuevo entramado agrario había un núcleo predominante de agricultores acompañados en forma desigual en diversos distritos por la emergencia de las colonias. Por ello, debe explorarse con mayor densidad ese conglomerado y ponderar adecuadamente el peso que tuvieron las colonias en el complejo proceso de transformación agraria entrerriana. A su vez, en las colonias, ubicadas centralmente en los distritos de Sauce, Espinillo, Tala y Antonio Tomás, se presentaba un escenario productivo que, en líneas generales, era muy similar al perfil presente en el resto de la campaña, con una mayoría dedicada a la agricultura, un 57,7 \%; seguida en orden decreciente por los actores dedicados al sector de los servicios y el comercio, un $33 \%$, y finalmente contaba en lo que marcaba la mayor diferencia con los distritos mencionados\# con un número muy menor de ganaderos, del orden del 1,9\%.

En segundo lugar, debemos destacar que la presencia de los inmigrantes en la producción agraria no fue sólo significativa en las colonias sino también en las innumerables unidades agrícolas que se desarrollaron en la mayoría de los distritos. Asimismo, se debe considerar que en las colonias no sólo hubo presencia de los extranjeros, sino que en algunas de ellas existió una participación importante de pobladores nativos, por lo cual el universo en la campaña y en las colonias fue diverso y complejo en términos productivos y étnicos.

Finalmente, una tercera consideración, a explorar con más información: se desprende del estudio que sobre los cambios en las características del mundo rural paranaense parece haber habido un sostenido aumento del acceso a la tierra de los productores, mucho más robusto que estimado en los registros oficiales de la provincia. En proporciones de intensidad, parece haber sido liderado sobre todo por las colonias, donde el porcentaje alcanzaba casi el $60 \%$ del total, y luego seguido por los agricultores, en tanto algo menor era el acceso en otros distritos rurales más ganaderos, donde llegaba a un 45,4\% del universo. De modo tal que la transformación sucedida no habría generado un esquema hiperpolarizado que diferenciaba las estructuras de producción y el acceso a la tierra entre las novedosas colonias agrícolas y las más tradicionales unidades productivas de los distritos rurales. Asimismo, aquello se correlaciona con el hecho de que en las colonias \#más allá de las claras diferencias que registraban entre sí\# se reflejaban en líneas generales, más acentuadas, las pautas que también estaban presentes en los otros actores de los distritos rurales.

Por tanto, nuestro análisis sobre la estructura de producción y modernización agraria nos devuelve una imagen dinámica del departamento de Paraná, en la que la colonización "radial” no fue una isla ni el único factor central, dado que emergió en los distritos junto con otro conjunto muy significativo de agricultores, estancieros y otros rubros de servicios y oficios, ya fuera en el área rural o en los pequeños poblados que constituían nodos con una fluida actividad productiva y de intercambios.

\section{RefEREnCias}

Barcos, M. F. (2013).Pueblosy ejidos de la campaña bonaerense. Una historia socio-económica de los derechos depropiedad y la conformación de un partido, Mercedes, 1780-1870. Rosario: Prohistoria.

Barsky, O. y Djenderedjian, J. (2003). Historia del capitalismo agrario pampeano. La expansión ganadera hasta 1895. Buenos Aires: Siglo XXI.

Barsky, O. y Gelman, J. (2011). Historia del agro argentino. Buenos Aires: Grijalbo-Mondadori.

Bonaudo, M. y Pucciarelli, A. (1993). La problemática agraria. Nuevas aproximaciones. Buenos Aires: CEAL.

Bressan, R. (2018). Alianzas, negociaciones y conflictos. Dinámicas de los elencos politicos del Litoral de los Ríos, 1862-1883. Rosario: Prohistoria.

Congreso de Entre Ríos (1887). Diario de Sesiones de la Cámara de Senadores del año 1884. Paraná: La Velocidad.

Cortés Conde, R. (1997). La economía argentina en el largo plazo, siglos XIX y XX. Buenos Aires: Sudamericana.

D 'Agostino, V. (2015). Estado, instituciones y funcionarios: la política de tierras y el funcionamiento de la repartición topográfica bonaerense en la segunda mitad de siglo XIX. En M. Blanco y L. Barandiarán (Comps.), Las configuraciones de la trama social (pp. 14-42). Tandil: UNICEN. 
De la Fuente, D., Carrasco, G. y Martínez, A. (1898). Segundo Censo de la República Argentina. Mayo 10 de 1895. Buenos Aires: Taller Tipográfico de la Penitenciaría Nacional.

Djenderedjian, J. (2008a). La colonización agrícola en Argentina, 1850-1900: problemas y desafíos de un complejo proceso de cambio productivo en Santa Fe y Entre Ríos. América Latina en la Historia Económica, 30, 127-157. doi: http://dx.doi.org/10.18232/alhe.v15i2

Djenderedjian, J. (2008b). Expansión agrícola y colonización en Entre Ríos, 1850-1900. Desarrollo Económico, 47 (188), 577-606.

Djenderedjian, J. (2013). Los costos de la modernización. La evolución del papel de la tierra en los patrimonios rurales entrerrianos, 1840-1895. En G. Banzato (Dir.), Tierras rurales. Politicas, transacciones y mercados en Argentina, 1780-1914 (pp. 65-94). Rosario: Prohistoria.

Djenderedjian, J. (2014). Tormenta perfecta. La rebelión jordanista en Entre Ríos y los efectos del ciclo económico 1864-1873. En D. Santilli, J. Gelman y R. Fradkin (Comps.), Rebeldes con causa. Conflicto y movilización popular en la Argentina del siglo XIX (pp. 169-195). Buenos Aires: Prometeo.

Djenderedjian, J., Bearzotti, S. y Martiren, J. (2010). Expansión agricola y colonización en la segunda mitad del siglo XIX. Buenos Aires: Teseo-UB.

Djenderedjian, J. y Schmit, R. (2008). Avances y límites de la expansión agraria Aargentina: crecimiento económico y distribución de la riqueza rural en Entre Ríos, 1860 y 1892. Investigaciones en Historia Económica, 11, 75-106.

Ferreyra A. y Tognetti L. (2018). Cuestiones Agrarias argentinas. La tierra como bien de producción, intercambio y factor de presión política. Buenos Aires: Imago Mundi.

Gallo, E. (1974). Boom cerealero y cambios en la estructura socio-política de Santa Fe. Buenos Aires: Instituto Di Tella.

Gallo, E. (1983). La pampa gringa. Buenos Aires: Sudamericana.

Gautreau, P. y Garavaglia, J. (Eds.). (2011). Mensurar la tierra, controlar el territorio. América Latina, siglos XVIII$X I X$. Rosario: Prohistoria.

Girbal, N. (1982). Historia de la agricultura argentina a fines del siglo XIX (1890-1900). Buenos Aires: Fondo de Cultura Económica.

González, M. (1874). Carta topográfica de la provincia de Entre Ríos con la demarcación de terrenosparticulares adoptada por el gobierno de la provincia en 1873. Entre Ríos: Gobierno de la Provincia.

Guzmán, V. (1879). Recopilación de leyes, decretos y disposiciones relativas a los campos de pastoreo, villas y colonias. Buenos Aires: Imprenta de Guillermo Kraft.

Guzmán, V. y Rígoli, B. (1886). Plano catastral de la provincia de Entre Ríos. Buenos Aires: Litografía José Ruland.

Halperín Donghi T. (1984). Canción de otoño en primavera: previsiones sobre la crisis de la agricultura cerealera argentina 1894-1930. Desarrollo Económico, 24 (95), 368-386.

Hora, R. (2010). Historia económica de la Argentina en el siglo XIX. Buenos Aires: Siglo XXI.

Martiren, J. (2016). La transformación farmer. Buenos Aires: Prometeo.

Míguez, E. (2008). Historia económica de la Argentina. De la conquista a la crisis de 1930. Buenos Aires: Sudamericana.

Ministerio de Gobierno. (1879). Informe del departamento Topográfico correspondiente al año 1879. Concepción del Uruguay: Gobierno de la Provincia.

Nolte, E. (1892). Plano Catastral de la provincia de Entre Ríos construido según los datos más recientes. Buenos Aires: Librería Alemana.

Popp, V. y Dening, N. (1977). Los alemanes del Volga. Buenos Aires: Talleres Gráficos Santo Domingo.

Rodríguez, D. y Flores, S. (2006). La colonización en Entre Ríos: la experiencia de la colonización ejidal, 1870-1890. Anuario del Centro de Estudios Históricos Prof. Carlos S. A. Segreti (6), 137-162

Schmit R. (2004). Ruina y resurrección en tiempos de guerra. Buenos Aires: Prometeo.

Schmit, R. (2007). Tradición y modernidad: inversiones y empresas rurales rioplatenses en tiempos de transición, 1840-1870. América Latina en la Historia Económica, 27, 85-114. doi:http://dx.doi.org/10.18232/alhe.v14i2 
Schmit, R. (2008). Los límites del progreso. Expansión rural en los orígenes del capitalismo rioplatense. Buenos Aires: Siglo XXI-UB.

Schmit, R. (2010). Derechos de propiedad, control social y poder durante la construcción del Estado nacional (Entre Ríos 1850-1870). En E. Bohoslavsky y M. Orellana (Comps.), Construcción estatal, orden oligárquico y respuestas sociales (pp. 65-92). Buenos Aires: Prometeo-UB-UNGS.

Schmit, R. (2015a). Estancias en Entre Ríos en la segunda mitad del siglo XIX. Mundo Agrario 16 (31). Recuperado de https://www.mundoagrario.unlp.edu.ar/ article/view/MAv16n31a01

Schmit, R. (2015b). Caudillos, política e Instituciones en los origenes de la nación Argentina. Los Polvorines: UNGS

Schmit, R. y Alabart, M. (2013). Cambio institucional y prácticas sociales en los orígenes del capitalismo rioplatense: Entre Ríos 1860-1878. Quinto Sol, 17 (1).doi: http://dx.doi.org/10.19137/qs.v17i1.598

Schmit, R. y Djenderedjian, J. (2007). La empresa rural en el largo plazo. Cambios en la explotación de una gran estancia rioplatense entre el orden colonial y el nacimiento del capitalismo, 1780-1870. Boletin del Instituto de Historia Argentina y Americana Dr. E. Ravignani, 29, 7-49.

Schmit, R. y Djenderedjian, J. (2011). La distribución de la riqueza en Entre Ríos 1840-1880: cambios en la inversión rural en un contexto difícil. En J. Gelman (Coord.), El mapa de la desigualdad en la Argentina del siglo XIX (pp.139.170). Rosario: Prohistoria.

Schmit, R. y Djenderedjian, J. (2010). Los límites de la gran empresa agraria en el nacimiento del capitalismo rioplatense. Una estancia entrerriana durante la primera mitad del siglo XIX. Anuario IEHS, 25, 395-414.

Scobie, J. (1968). Revolución en las pampas. Historia social del agro argentino, 1860-1910. Buenos Aires: Sola-Hachette. Weyne, O. (1987). El último puerto. Del Rhin al Volga y del Volga al Plata. Buenos Aires: Tesis -Instituto Di Tella.

Weyne, O. (1988).Descripción de un ciclo de colonización agricola. Entre Rios entre 1870 y 1914. Buenos Aires: Instituto Di Tella.

\section{Notas}

1 De la Fuente, Carrasco y Martínez (1898). Segundo Censo de la República Argentina de 1895, Tomo 3, XXXIX. Las cifras de 1872 son estimaciones. También estos datos han sido tomados como referencia por el trabajo de Djenderedjian, Bearzotti y Martiren (2010).

2 Para este trabajo se utilizan solamente los registros de las cédulas censales de población del Censo Nacional de 1895.

3 Las fichas censales del censo nacional de 1895 fueron tomadas del Archivo General de la Nación (AGN). En él se indican los datos básicos para cada unidad censal. De las variables del censo, para nuestro estudio tomamos: provincia, departamento, distrito, lugar o pueblo, ámbito (urbano o rural), nombres, edad, sexo, estado civil, origen, tipo de ocupación, acceso a la propiedad. Hemos respetado la división que presenta el censo sobre el recorte espacial de los distritos, pueblos, colonias y ejidos.

4 AGER. Fondo Gobierno, Datos censales del Departamento de Paraná, Informes de los Jefes Políticos en 1861, sección política.

5 Las unidades censales fueron elaboradas sobre la base de los datos declarados en el Censo Nacional de 1895 para cada unidad familiar censada.

6 Respecto de la información específica de las tablas sobre las colonias, para este caso hemos agrupado las colonias en un solo distrito, pero algunas de ellas, como Colonia Crespo y Cerrito, se encontraban situadas en dos distritos diferentes.

7 En 1861, la ley sancionada bajo el título de "venta de 400 leguas de pastoreo" estableció que, además de los propietarios con títulos reconocidos por el Gobierno provincial, habría desde entonces diferentes derechos sobre la tierra para una vasta cantidad de pobladores, entre los que se diferenciaba a los poseedores con algún tipo de habilitación por el Estado de los meros ocupantes de tierras fiscales. El artículo 13 estableció que a los poseedores con menos de 20 años de antigüedad se les concedía como propiedad sólo la tercera parte del terreno que hasta entonces poseían. En cambio, el artículo 14 de la ley fijó que a aquellos con más de 20 años de posesión se les reconocía en propiedad la mitad del terreno que usufructuaban. Las fracciones de terreno que no fueran otorgadas en propiedad podían, desde ese momento, ser arrendadas al Estado. Sin embargo, por lo menos hasta la década de 1880 pocos poseedores convalidaron sus títulos en el Departamento Topográfico y regularizaron sus derechos sobre las tierras. Por lo tanto, el complejo y dinámico proceso sucedido entre propietarios, arrendatarios, poseedores y ocupantes es registrado entre 1860 y 1890 de forma parcial e incompleta en la documentación catastral. Más allá de lo expuesto, en este artículo utilizamos para abordar la cuestión 
de la propiedad las categorías de propietario (de derecho o de usufructo) y no propietario tal cual fueron informadas en las cedulas del censo nacional de 1895 .

8 La ley del 19 de agosto de 1871 estableció que el Departamento Topográfico estaba encargado de intervenir en todo lo relativo a la demarcación y limitación de la propiedad territorial en toda la provincia. La relevancia del organismo en esta tarea fue respaldada, a su vez, por disposiciones posteriores.Los decretos del 29 de julio y del 9 de agosto de 1872 enfatizaron la obligación que tenían los escribanos de remitir a esa dependencia la relación de las enajenaciones de propiedad, posesión o arrendamiento en que hubiesen intervenido y se establecía que los jefes políticos no podían conceder ningún solar ni chacra ni tampoco iniciar obra pública alguna sin la autorización correspondiente de las autoridades del Departamento Topográfico. En forma similar, las leyes de venta y de arrendamiento de tierras públicas del 23 de marzo y del 20 de mayo de 1872 planteaban que toda solicitud de compra o arrendamiento debía ser informada al Departamento Topográfico, a cuyas autoridades correspondía examinar y/o confeccionar las mensuras y establecer el avalúo de los campos. Legajo 1. AGER. Fondo Gobierno, Serie VI Leyes y Decretos, Caja 9.

9 Este sistema de recopilación de la información topográfica no fue privativo de Entre Ríos sino que fue implementado en otras provincias del Río de la Plata, como plantean, entre otros, Gautreau y Garavaglia (2011) y D 'Agostino (2015).

10 En esos registros de 1879 se presentaba el siguiente panorama por distrito: en Sauce, 13 propietarios y 9 arrendatarios. Espinillo, 10 propietarios y 39 arrendatarios. Tala, 13 propietarios y 9 arrendatarios. Antonio Tomás, 2 propietarios y 6 arrendatarios. Quebracho, 10 propietarios y 39 arrendatarios. María Grande, 14 propietarios y 17 arrendatarios. En total, 62 propietarios y 115 arrendatarios.

11 Decreto del 25 de octubre de 1860 (Guzmán, 1879).

12 Ley del 8 de marzo de 1875 (Guzmán, 1879).

13 En los debates realizados en la Cámara de Senadores se rechazó la propuesta de fijar el precio de las concesiones en general en 100 pesos. En este sentido, el senador Morán argumentó que ese monto era muy escaso para algunos departamentos como Paraná o Rosario Tala, donde las parcelas se habían vendido en las colonias privadas en montos que variaban entre los 100 y los 250 pesos. En cambio, en Villaguay las parcelas se ofrecían a 40 pesos y aun así era difícil encontrar comprador (Congreso de Entre Ríos, 1887). 